ISSN 1518-3483

Licenciado sob uma Licença Creative Commons

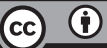

\title{
Uma política de formação voltada aos professores iniciantes de Sobral - CE
}

\section{A training policy geared to beginning teachers in Sobral - CE}

\section{Una política de formación dirigida a los profesores \\ principiantes de Sobral - CE}

\author{
Ana Maria Gimenes Corrêa Cali|[a], Marli Eliza Dalmazo Afonso de André[b]* \\ [a] Universidade de Taubaté (UNITAU), Taubaté, SP, Brasil \\ [b] Pontifícia Universidade Católica de São Paulo (PUCSP), São Paulo, SP, Brasil
}

\section{Resumo}

O objetivo desta pesquisa foi analisar a política de formação continuada dos professores iniciantes no município de Sobral (CE). A educação neste município tem chamado a atenção tanto por apresentar evolução nos indicadores de avaliação quanto por realizar formação continuada específica aos professores iniciantes na rede municipal. Foi adotada a abordagem qualitativa de pesquisa e utilizados diferentes procedimentos e instrumentos de pesquisa, tais como: grupo

AMGCC: Doutora em Psicologia da Educação, e-mail: ana.calil@unitau.com.br MEDAA: Doutora em Psicologia da Educação, e-mail: marliandre@pucsp.br 
focal, observação, análise de documentos e questionário na tentativa de captar o processo de formação continuada. Criou-se uma Escola de Formação Permanente, responsável pela formação dos professores. Os sujeitos foram a diretora e a coordenadora de formação da Escola de Formação de Professores e mais 46 professores iniciantes que avaliaram a formação oferecida pela rede municipal. Os resultados apontaram um grau de satisfação positivo dos professores iniciantes em relação ao desenvolvimento profissional proporcionado pelo processo de formação continuada específica aos iniciantes.

Palavras-chave: Formação continuada. Professores iniciantes. Desenvolvimento profissional.

\begin{abstract}
The focus of this research was to analyze teacher education policies for beginning teachers in the city of Sobral, Ceará, Brazil. Education in this city has been calling attention as for presenting evolution on evaluation assessments as for bringing up teacher continued education for beginner teachers in the municipal schools. Qualitative research approach was adopted and different procedures and instruments were used, such as: focus group, observation, analysis of documents and questionnaire, attempting to track the process of teacher continued education. A Permanent Education School was created to take care for teachers' qualification. The research subjects were the principal and the coordinator of qualification of the Teacher Qualification School and 46 beginner teachers that were taking instructions and evaluating the training offered by the municipal. The results point to a positive level of beginner teachers' satisfaction in relation to the professional development offered by the process of teacher continued education, specifically for beginners.
\end{abstract}

Keywords: Teacher continued education. Beginner teachers. Professional development.

\title{
Resumen
}

El objetivo de este estudio fue analizar la política de formación continua de los profesores principiantes en el municipio de Sobral, Ceará, Brasil. La educación en este municipio ha llamado la atención tanto de presentar la evolución de los indicadores de evaluación como para la formación continua específica para los profesores principiantes en las escuelas públicas. Se adoptó un enfoque cualitativo y utiliza diferentes procedimientos y 
herramientas de investigación, tales como grupos focales, observación, análisis de documentos y cuestionario en un intento de capturar el proceso de formación continua. Una Escuela de Formación Permanente fue establecida para hacerse cargo de la formación de profesores. Los sujetos fueron el director y el coordinador de la formación en la Escuela de Formación de Profesores y 46 profesores principiantes que evaluó la formación ofrecida por la red municipal. Los resultados muestran un grado de satisfacción positiva de los profesores principiantes en el desarrollo profesional proporcionado por el proceso de formación continua específica para los principiantes.

Palabras clave: Educación continua. Profesores principiantes. Desarrollo profesional.

\section{Introdução}

O período de inserção profissional é, de acordo com Marcelo (2011), uma das etapas mais importantes, mas também a mais desatendida no processo de aprender a ensinar. Ter que atender às exigências de ensinar e aprender a ensinar ao mesmo tempo não é uma tarefa fácil, tampouco, quando se cobra da escola pública uma educação de qualidade. É consensual o pensamento de que o início da carreira é um período marcante em qualquer profissão e com a docência não é diferente (ROMANOWSKI; MARTINS, 2010; REALI; TANCREDI; MIZUKAMI, 2008). As primeiras experiências na sala de aula servem como um teste para a continuidade ou desistência da profissão (LIMA et al., 2007).

Quando muitos países, tanto da Europa quanto das Américas, perceberam o quão difícil era atrair e manter na docência os melhores professores, teve início a preocupação com este período da profissão docente; dificuldade que aumentava em determinadas matérias do currículo e nas escolas menos favorecidas (OCDE, 2006; VAILLANT, 2006; MARCELO, 2011).

Portanto, como bem destaca Ávalos (2012), deve haver interesse em reconhecer a importância desse período de inserção profissional e suas peculiaridades, no sentido de as políticas públicas apoiarem-no formalmente como já acontece em alguns países, tais como o Chile, Austrália 
e Inglaterra. Nesses países, há políticas e processos de indução que evidenciam efeitos sobre as condições de trabalho dos professores iniciantes, sobre seu bem-estar profissional, sobre o sentido da autoeficácia, bem como, a qualidade de sua prática e sua retenção nas escolas.

Tema silenciado por muitos anos — os professores iniciantes volta a ser tratado, no Brasil, a partir de estudos como os de Mizukami e Reali (2002); Montalvão e Mizukami (2002); André (2009); Gatti (2010); Romanowski e Martins (2010); Pappi (2011), Gatti, Barreto, André (2011); Romanowski (2012); Papi (2012), Gabardo (2012), Corrêa e Portela (2015), Cunha et al. (2015), entre outros.

Ações efetivas voltadas especificamente aos iniciantes são quase inexistentes no Brasil. Daí o nosso interesse em analisar a experiência de Sobral, no Ceará, que foi apontada por Gatti, Barreto e André (2011) como um dos raros exemplos de política de formação dos iniciantes no Brasil. Antes, porém, de comentarmos os dados desta investigação, vale retomar o que diz a literatura sobre os conhecimentos e saberes necessários aos professores que iniciam a docência.

\section{O que os professores iniciantes precisam saber}

Os professores iniciantes se deparam com um cenário bastante complexo quando chegam a uma escola, necessitam dominar os conteúdos disciplinares e saber como transformá-los em pedagógicos, de modo a atender às necessidades dos alunos, ter bom manejo de sala de aula, adaptar-se ao clima e à cultura da escola (DARLING-HAMMOND; BARATZSNOWDEN, 2005; GATTI, 2012).

Darling-Hammond e Baratz-Snowden (2005) descrevem um conjunto de ideias, habilidades e disposições essenciais a serem adquiridas pelos professores iniciantes. Elas destacam que os iniciantes devem saber sobre "aprendizagem, desenvolvimento humano, linguagem, currículo, matéria a ser ensinada, sobre como ensinar uma diversidade 
de alunos, sobre avaliação e gerenciamento de sala de aula" (DARLINGHAMMOND; BARATZ-SNOWDEN, 2005, p. 7).

As autoras também discorrem sobre a complexidade que é característica da profissão. Muitas dúvidas assolam o dia-a-dia do professor iniciante:

O que ensinarei entre tudo o que deveria ensinar? Como posso compreender isso para que o meu entendimento torne o deles possível? $\mathrm{O}$ que estão pensando e sentindo em relação a mim, uns aos outros e em relação ao que estou tentando ensinar? Quão perto eu deveria vir e quão longe eu deveria ficar? (DARLING-HAMMOND, BARATZSNOWDEN, 2005, p. 38).

Todas estas questões habitam a mente do professor enquanto ensina. Darling-Hammond e Baratz-Snowden (2005), propõem um conjunto de conhecimentos, práticas, disposições e ferramentas que denominam de "estrutura para aprender a ensinar", composta por: conhecimentos (compreensão do conteúdo ou matéria, pedagogia, alunos e seus contextos sociais), práticas (um repertório inicial de estratégias de ensino), visão (imagens de boas práticas que guiem o ensino), disposições (hábitos de pensamento e ação sobre o ensino e as crianças) e ferramentas (recursos conceituais e procedimentais para usar em sala de aula), todas elas inter-relacionadas.

Para colocar esta estrutura em prática e para que seja mais efetiva, é necessário, segundo as autoras, realizar parcerias entre os cursos de formação e as escolas que comporão as comunidades de aprendizagem, onde os professores experientes atenderão aos grupos de alunos-professores, compartilhando regras, práticas e comportamentos que influenciarão, sobremaneira, sua aprendizagem.

No contexto nacional, a formação dos iniciantes em Sobral (CE) é considerada bem-sucedida. Ouvir o que dizem os formuladores da política local e os agentes diretamente envolvidos na formação - formadores e professores - pode indicar caminhos para ações e medidas eficazes no contexto brasileiro. 


\section{Metodologia da pesquisa}

Foi adotada a abordagem qualitativa de pesquisa que se caracteriza pelo estudo de uma situação em sua complexidade e totalidade, levando em conta o contexto em que se desenvolve e os significados atribuídos pelos sujeitos àquela situação (ANDRÉ, 1995).

Por tratar-se de políticas de formação continuada, foi necessário focar em três lócus diferentes, mas interdependentes, a fim de abranger o maior número possível de agentes envolvidos neste processo. O primeiro local foi a SEMED (Secretaria Municipal de Educação), onde foram realizadas entrevistas com a Superintendente Educacional e com a Coordenadora de Valorização do Magistério; o segundo, foi a ESFAPEM (Escola de Formação Permanente do Magistério), onde os dados foram colhidos também por meio de entrevista com a Diretora, com a Coordenadora da Formação Continuada e com questionários de 11 professores formadores. Por último, na Vila Olímpica, espaço onde acontecem as formações, foram obtidos os dados com 46 professores iniciantes, sendo 36 por meio de questionários e 10 por meio de grupo focal.

Foram conjugados três tipos de instrumentos: questionário, entrevista e grupo focal. Os questionários foram utilizados quando se tratava de abrangência a um número maior de pessoas, como foi o caso dos formadores, no qual foram enviados 11 questionários que retornaram respondidos e dos professores iniciantes, em que dos 108 enviados, retornaram 36 respondidos.

Para este artigo foi realizado um recorte da pesquisa e trazidos dados parciais obtidos junto à Diretora e Coordenadora da ESFAPEM e dos professores iniciantes no grupo focal.

\section{A formação continuada dos professores iniciantes em Sobral (CE)}

Os dados aqui apresentados para o histórico da formação são originados de entrevistas realizadas com a diretora e a coordenadora da ESFAPEM. 
No final da década de 90, eram propostas formações esporádicas realizadas por um grupo de profissionais da SEMED. Durante o estágio probatório de três anos, os professores passavam, semestralmente, por avaliações sistemáticas de desempenho, compostas por: uma autoavaliação, somada a uma avaliação do diretor, que incluía desde a assiduidade até o desempenho do professor em sala de aula, e um relatório de observação feito pela equipe da SEMED.

As discussões sobre a formação para os iniciantes tiveram início em meados dos anos 2000, momento em que houve também discussões sobre o plano de carreira e a percepção de que era preciso dar suporte e apoio ao professor que estava ingressando. Foi implantado, neste ano, o Conselho Municipal de Educação, que constituiu um grupo de trabalho para estudar as questões da carreira docente.

Em 2005, foi criada a ESFAPEM, com espaço próprio, independente da SEMED, que atenderia tanto a formação em serviço quanto a valorização do magistério por meio de ações de formação pessoal e cultural. As primeiras ações da ESFAPEM concretizaram-se em 2006, uma vez que o ingresso de professores no concurso de 2005 revelou lacunas em sua formação, o que reforçou a necessidade de um programa de formação que atendesse aos professores que estavam iniciando sua experiência docente. De acordo com as entrevistadas, a iniciativa pretendia capacitar adequadamente os professores iniciantes, a fim de que atendessem à demanda do município e, ao mesmo tempo, os aproximasse da realidade educacional.

Foi criada a formação para professores iniciantes na rede municipal, cuja participação, durante o estágio probatório é compulsória. Os professores recebem um incentivo financeiro de $25 \%$ do salário base de 4 horas.

Esta modalidade de formação compreende uma carga horária de 200 horas/aula, com frequência mínima de 80\% da carga horária. Passou a vigorar a partir do concurso de 2007 e os professores que ingressaram por concurso neste mesmo ano, realizaram o curso de formação em 2008 e 2009. 
O primeiro formato do curso tinha uma orientação voltada, principalmente, para as áreas de Língua Portuguesa e Matemática. Independente da área de atuação, todos os professores ingressantes deveriam cumpri-lo. Os eixos norteadores eram: Programa de Modificabilidade Cognitiva e Aprendizagem Mediada - PEI (Programa de Enriquecimento Instrumental), 30h/a; Matemática, 60h/a; Língua Portuguesa, 60h/a e Ampliação do Universo Cultural — Programa Olhares, 50h/a. A divisão dos encontros dava-se da seguinte forma: encontros semanais com 1 hora/ aula para o Programa de Modificabilidade Cognitiva e Aprendizagem; dois encontros mensais para o trabalho, sob a forma de seminários de estudo e discussão de Matemática e Língua Portuguesa; e a Ampliação do Universo Cultural, desenvolvida por meio da participação dos professores, nas atividades do Programa Olhares ao longo do ano.

Após a primeira experiência e a avaliação dos professores concluintes, fez-se necessária uma modificação. A predominância da Língua Portuguesa e da Matemática, atendia apenas aos professores polivalentes, ou seja, apenas uma parcela dos ingressantes, os pedagogos. Outro ponto considerado para a modificação foi a fragilidade apresentada pelos professores no âmbito pedagógico, que tornou imperativo a promoção de uma visão mais ampliada sobre a educação.

A SEMED e a ESFAPEM resolveram modificar a estrutura do curso. Tal ajuste nos módulos do programa procurou atender melhor os ingressantes de diversas áreas, sobretudo Educação Física, História, Geografia e Letras, além da Pedagogia.

O novo modelo de formação teve duas preocupações: a primeira, preparar os sujeitos com o propósito de ajudá-los a superar "os entraves e dificuldades que encontram no exercício profissional, relativos à falta de conhecimentos científicos e essenciais e de habilidade para o adequado manejo de sala de aula" (DAVIS et al., 2012, p. 12). A segunda, consiste no atendimento às necessidades específicas do momento profissional em que se encontram os iniciantes, respeitando o ciclo de vida profissional, além de procurar contribuir para a ampliação do universo cultural - caso do Programa Olhares, que permaneceu como um dos módulos da formação. 
A coordenadora continua a análise das principais necessidades dos professores, percebidas pelos organizadores do curso:

\begin{abstract}
Então foi uma dimensão maior, mais ampla, que preparasse o professor dentro de uma visão mais da relação com o aluno; da relação com o colega professor; com a gestão da escola; com o gestor da escola. De prepará-los mais pra essa atuação mais ampla dentro do contexto escolar. Então, esse último curso, que eles estão concluindo agora, foi bem diferente do primeiro que era mais uma visão de conteúdo, trabalho com conteúdo (COORDENADORA DA ESFAPEM).
\end{abstract}

As 120 horas dispensadas à Língua Portuguesa e a Matemática, foram transformadas em módulos com caráter mais pedagógico e mais relacional e as 50 horas do Programa Olhares foram diminuídas para 30 horas. A segunda proposta, também de $200 \mathrm{~h} / \mathrm{a}$, passou a ter a seguinte composição: Modificabilidade Cognitiva - 40h/a; Contexto Escolar, 20 h/a; Contexto Sociocultural, 20h/a; Relações Interpessoais na Escola e Ética Profissional, 35h/a; Didática e Metodologia de Ensino na Educação Básica, 35h/a; Formação Pessoal e Cultural, 30h/a (participação no Encontro de Professores do Projeto Olhares e em outras atividades do Projeto que totalizem a carga horária estabelecida); Apresentação dos Projetos de Pesquisa realizados durante a formação, 20h/a.

A diretora da ESFAPEM relata que algumas mudanças foram percebidas ao longo deste ano em que os iniciantes frequentaram o curso de formação:

Com a formação do estágio probatório, o que eu venho percebendo é como está sendo interessante para a construção da relação do coletivo da escola, sabe? A construção da relação do professor com o diretor, com o coordenador pedagógico no momento em que eles precisam estar ali, estudando toda a escola. Ele não chega e fica... ele passa a perceber que a escola não é só a sala de aula dele. Que a escola é a escola toda, é o vigia, o trabalho e a comunidade. Quando tem também o módulo que ele precisa trabalhar as relações família e comunidade, a vizinhança ali da escola. Então a gente viu o quanto isso está sendo importante para a própria escola como instituição e para 
o professor sentir o espaço escolar como um espaço em construção para a formação dele (DIRETORA DA ESFAPEM).

De acordo a coordenadora da ESFAPEM, para o próximo grupo de ingressantes serão realizados novos ajustes, baseados nas demandas e experiências com o grupo anterior.

No momento da revisão para elaboração do novo curso, estão envolvidos os professores formadores, a equipe da ESFAPEM e da SEMED que também levam em conta a avaliação dos participantes do curso. Os professores iniciantes frequentam simultaneamente dois programas de formação, um específico para ingressantes na rede - este do estágio probatório - e, outro de formação continuada, junto com outros professores da rede que trabalham nas mesmas séries ou áreas. Desta forma, entram em contato com duas formações que, embora distintas, são complementares. Segundo a diretora da ESFAPEM:

O estágio probatório é para o professor sentir o espaço escolar como espaço de construção pra formação dele. E a formação em serviço já tem outra estrutura que é a competência e o ofício do magistério, a competência pedagógica no sentido da eficiência do trabalho em sala de aula. A formação em serviço é voltada pra o que acontece dentro da sala de aula (DIRETORA ESFAPEM).

Naturalmente, uma formação de 200 horas não supre todas as lacunas pedagógicas apresentadas pelos iniciantes, mas ao longo desse período é preciso considerar que eles estão "assistidos pedagogicamente" em pelo menos três momentos: período do estágio probatório; formação realizada com os demais professores e planejamento, na escola, com o coordenador pedagógico.

O espaço de trocas permite que o professor iniciante ao extrapolar a sua experiência singular caminhe no sentido da construção do seu conhecimento profissional, referendado pela reflexão e pela tomada consciente de decisões no âmbito da prática (IMBERNÓN, 1998). 
A intenção do programa de formação no estágio probatório é uma tentativa de levar os professores a conhecerem melhor seu ambiente de trabalho e refletirem sobre as necessidades da prática, sobre as demandas do contexto em que atuam.

Percebe-se que a proposta de formação dos professores iniciantes em Sobral, aparece, conforme afirma Nóvoa (2009), como a construção de uma política de educação que reforça os professores e seus saberes, reforça o seu campo de atuação, bem como, valoriza a cultura docente. Ao propor uma formação para professores iniciantes que promove a sua entrada na rede de ensino, na própria profissão e no contexto escolar, os gestores estão contribuindo para a apropriação de conhecimentos profissionais e para o desenvolvimento profissional desses professores.

A formação realizada em Sobral parece fazer com que os professores iniciantes percebam e pensem a profissão "do lado de dentro", no sentido de não falarem sobre algo observado, mas sim, vivido. São orientados a perceber que os contextos que condicionam suas ações na sala de aula exigem não apenas a competência técnica, mas a competência intelectual e relacional. A formação do estágio probatório e a inserção na escola favorecem aos professores iniciantes a aproximação e o alinhamento das suas expectativas com as da escola e as da Secretaria.

\section{Como os professores iniciantes veem a formação}

No grupo focal, os professores comentaram o valor da formação que receberam e a contribuição dos formadores. O depoimento a seguir corrobora essa avaliação:

E pra mim foi uma experiência bastante rica porque, além das aulas proporcionadas pelos professores, algo que eu considero que me fez crescer muito também foi a própria troca de experiência. Já que estamos num grupo de professores, todos que estão aqui são professores, alguns mais recentemente outros há mais tempo. Esse intercâmbio de experiência, pra mim, foi muito 
rico além da própria... das aulas dos professores. Pra mim foi muito interessante! (P2).

Similar ao depoimento anterior, o comentário da professora de que a formação foi "bastante rica" abrangeu dois aspectos: as "aulas" dos formadores e a oportunidade de troca de experiências. Sobre as aulas dos formadores, infere-se que foram momentos de aprendizagem, de incremento ao seu desenvolvimento profissional. A troca de experiência entre os colegas possibilita o compartilhamento de práticas de sala de aula, o que é proporcionado pela reunião de iniciantes e experientes.

A oportunidade de trocar experiências é muito valorizada pelos professores, pois ameniza suas ansiedades. Essa formação os fez perceber também o caráter relacional da profissão, como declara uma professora:

Eu achei bem interessante. O material que a gente trabalha vem todo voltado pra formação do professor em sala de aula. Eu só fiz dois módulos. Entrei também no meio do ano, fiz Didática e a parte de Ética e Relações Pessoais [...] Eu achei muito interessante porque isso vem enriquecer o nosso trabalho, é uma formação continuada e que eu acho que deve continuar sendo feita porque valoriza mais a carreira do magistério (P3).

Ao afirmar que o material está voltado para o professor em sala de aula e entusiasmar-se com isso, a depoente reforça o encantamento com questões da prática, questões essas, nem sempre tratadas nos cursos de formação inicial. Esta aproximação da Didática com a prática, com a realidade da escola tem sido recorrentemente valorizada pelos professores.

Parece que as instituições promotoras da formação de Sobral atenderam em alguns aspectos às necessidades dos principiantes, às novidades características e peculiares do início profissional: desenharam uma formação que foi efetiva porque atingiu as lacunas dos ingressantes, conforme explicitados nos exemplos abaixo:

Porque quando a gente é das Exatas fica muito avessa às leituras, se apega muito aos cálculos e a gente esquece muito a teoria. E essa formação pra 
mim foi importante porque eu tive que voltar e procurar estudar pra poder... eu ter um embasamento teórico, pra aplicar os meus projetos. Então, pra mim, foi enriquecedor. Eu acho que dentro de todas essas experiências, de aprendizado que eu tirei daqui foram de grande importância para minha prática (P8).

[...] nos cursos de formação acadêmica nem sempre a gente consegue absorver tudo porque a Didática é muito vasta. Então se a expectativa é propor uma mudança de paradigmas, de ações, de atuações do professor, a gente precisa ler, estudar e participar de outras experiências (P4).

Até porque a gente tem trabalhado projetos e é o que coloca a gente na situação prática da sala de aula. Então, dessa forma, pra mim, foi bastante gratificante (P1).

Os extratos acima ressaltam três aspectos importantes para o desenvolvimento profissional dos professores iniciantes: o estabelecimento da relação existente entre a teoria e a prática; a necessidade de leitura, estudo e atualização; e o amparo metodológico no trabalho com o método de projetos. E, novamente, os professores elogiam a formação como enriquecedora, muito importante e gratificante.

Para Day (2001, p. 85), os professores iniciantes são os mais dispostos a buscar a aprendizagem: “[...] os aprendentes vorazes são aqueles professores que se encontram no início da carreira, professores no seu primeiro ano de ensino, que se preocupam desesperadamente em aprender o seu novo ofício". De certa forma, os desafios da ação docente obrigam os iniciantes a pensar seu conteúdo pedagogicamente e a sair da zona de conforto, partindo para a autoformação, desencadeiam um processo interno de busca, não apenas para atender a outrem, mas sim, para dar conta de suas próprias questões.

Fortalecer suas experiências, compartilhá-las, poder contar com apoio dos formadores para o esclarecimento de dúvidas e fugir do isolamento da sala de aula, faz com que se sintam "assistidos" e "apoiados", além de contribuir para o desenvolvimento profissional dos professores iniciantes, como afirma a professora: 
O bom disso aqui é você estar numa sala e conhecer a realidade dos outros e ai se enxergar, se reconhecer, se avaliar, tentar melhorar e reconhecer o lado do outro e tudo. Isso foi muito bom pra mim! E foi muito bom sair um pouco só da Educação Física. Falava muito com professores de Matemática, com os outros, com outras linguagens. (P5).

A professora ressalta a riqueza da troca de experiência que a maioria dos professores evidenciou. Neste caso, não foi apenas dividir e compartilhar as experiências, mas enxergar o outro como profissional, que detém um saber específico, mas que enfrenta questões comuns. Nóvoa (2009, p. 06), enfatiza que os professores devem ter um lugar na formação dos seus colegas. "Não haverá nenhuma mudança significativa se a 'comunidade de formadores de professores' e a 'comunidade dos professores' não se tornarem mais permeáveis e imbricadas". O contato entre os professores é imprescindível para o seu desenvolvimento profissional.

Além de aprender a ver e ouvir o outro, desenvolve a alteridade e, através do outro ela se vê, se revê e se autoavalia. Esse é um aspecto fundamental no desenvolvimento profissional do docente: dispor-se a se rever, a analisar suas ações e a mudar. A relação dialógica com o outro também foi enriquecida por ser estabelecida entre sujeitos de diferentes áreas e segmentos. A visão do professor é ampliada ao se conhecer as preocupações e sistemáticas, que vão da Educação Infantil ao Ensino Médio, que extrapolam os saberes da Educação Física para abranger outras áreas, outras particularidades e linguagens.

Um dos professores cedeu esta declaração em relação à formação para os iniciantes:

Nós estamos aqui, a gente brinca, a gente reclama, mas a gente sabe que é preciso. Não tem como ser um bom professor se você não tiver sendo influenciado a todo o momento. Sem essa troca de experiências, e é claro, a Secretaria tem que fazer isso nem que seja obrigatório mesmo. Porque a história do estudar é importante em qualquer das profissões, imagine a nossa. Imagine a nossa! Nós, primordialmente precisamos estudar, estar em contato com outras experiências e claro, sim, a questão da continuação. 
Eu acredito que o formato de cada formação, a cada novo ano ela vai sendo diferente, a proposta da formação passada foi bem diferente da nossa (P6).

O professor destaca não só o valor da troca de experiências e o incentivo para o estudo constante, mas também ressalta a mudança, a cada ano, do formato das ações formativas, para melhor atender os grupos de professores, sem impor uma proposta pronta.

Os professores apontaram poucas críticas, que, em geral, são relacionadas a necessidade de maior aprofundamento teórico. Os depoimentos abaixo expressam a opinião de apenas dois dos 10 professores do grupo focal:

Deveria ter sido dado mais material, mais teoria, ter sido estudada uma coisa muito maior que transformasse essa experiência que a gente tem em algo muito mais voltado pra teoria também. Eu acho que a gente merece, eu acho que a gente precisa dessa... sair desse bom senso (senso comum) (P4).

Eu acho que faltou um pouco de aprofundamento em relação a muitas coisas. Com relação à troca é muito prazeroso, mas quando você se questiona e quando não vem uma resposta... isso nós aprendemos com as nossas experiências. A que nome se dá isso né? Saber da experiência... (P6).

Os depoimentos evidenciam, por um lado uma necessidade de teorizar, e por outro lado, a insatisfação com a troca de experiência que não ajuda a encontrar respostas.

\section{Considerações finais}

Os dados da pesquisa mostraram sensibilidade dos gestores da política de Sobral (CE) no reconhecimento das necessidades específicas dos iniciantes, o que os levou a implantar um processo de formação voltado para esse grupo de profissionais e que responde ao apelo de Marcelo 
(2011) para que haja uma atenção especial a essa fase do desenvolvimento profissional. Desconhece-se experiência semelhante no Brasil.

Os dados também evidenciaram uma disposição dos gestores para a revisão da proposta de formação, levando em conta a avaliação dos resultados obtidos. O levantamento das opiniões dos professores iniciantes sobre a formação que lhes é oferecida mostrou um grau de satisfação generalizado sobre sua contribuição para o trabalho de sala de aula e para o seu desenvolvimento profissional.

Para os professores iniciantes, a dimensão da "eficiência", também evidenciada por Vaillant e Marcelo (2012), assume um papel psicológico importante. Segundo os autores, em qualquer nível ou área de conhecimento, os professores iniciantes desejam orientações sobre o passo a passo, sobre como proceder com eficiência na sala de aula.

\section{Referências}

ANDRÉ, M. E. D. A. Etnografia da prática escolar. Campinas: Papirus, 1995.

ANDRÉ, M. E. D. A. A produção acadêmica sobre formação docente: um estudo comparativo das dissertações e teses dos anos 1990 e 2000. Revista Brasileira de Pesquisa sobre Formação de Professores, v. 1, n. 1, p. 41-56, ago./dez. 2009.

ÁVALOS, B. Hacia la configuración de políticas de inducción para profesores principiantes. In: CONGRESO NTERNACIONAL SOBRE PROFESORADO PRINCIPIANTE E INSERCIÓN PROFESIONAL A LA DOCENCIA, 3., 2012, Santiago de Chile. Anais... Santiago de Chile: UA, 2012. 1 CD-ROM.

CORRÊA, P. M.; PORTELLA, V. C. M. As pesquisas sobre professores iniciantes no Brasil: uma revisão. Olhar de Professor, v. 15, n. 2, p. 223-236, 2012. Disponível em: <http://www.revistas2.uepg.br/index.php/olhardeprofessor/article/view/4287/3270>. Acesso em: 29 mai. 2015. 
CUNHA, M. C.; BRACCINI, M. L.; FELDKERCHER, N. Inserção profissional, políticas e práticas sobre a iniciação à docência: avaliando a produção dos congressos internacionais sobre o professorado principiante. Avaliação, v. 20, n. 1, p. 73-86, mar. 2015.

DARLING-HAMMOND, L.; BARATZ-SNOWDEN, J. (Eds.) A good teacher in every classroom: preparing the highly qualified teachers our children deserve. The National Academy of Education. Committee on Teacher Education. San Francisco: John Wiley \& Sons, 2005.

DAVIS, C. L. F. et al. Formação continuada de professores: uma análise das modalidades e das práticas em estados e municípios brasileiros. São Paulo: FCC/DPE, 2012.

DAY, C. Desenvolvimento profissional de professores: os desafios da aprendizagem permanente. Porto: Porto Editora, 2001.

GABARDO, C. V. L. O início da docência no Ensino Fundamental da rede municipal de Joinville/SC. 2012. 127 f. Dissertação (Mestrado em Educação) Universidade da Região de Joinville (UNIVILLE), Joinville, 2012.

GATTI, B. A. Formação de professores no Brasil: características e problemas. Educação e Sociedade, v. 31, n. 113, p. 1355-1379, out./dez. 2010.

GATTI, B. A. O início da carreira docente no Brasil: formas de entrada, primeiras experiências profissionais e políticas educacionais. In: CONGRESO INTERNACIONAL SOBRE PROFESORADO PRINCIPIANTE E INSERCIÓN PROFESIONAL A LA DOCÊNCIA, 3., 2012, Santiago de Chile. Anais... Santiago de Chile: UA, 2012. 1 CD-ROM.

GATTI, B. A.; BARRETO, E. S. S.; ANDRÉ, M. E. D. A. Políticas docentes no Brasil: um estado da arte. Brasília: UNESCO, 2011.

IMBERNÓN, F. La formación y el desarrollo profesional del profesorado: hacia una nueva cultura profesional. 3. ed. Barcelona: Graó, 1998. 
LIMA, E. F. et al. Sobrevivendo ao início da carreira docente e permanecendo nela. Como? Por quê? O que dizem alguns estudos. Educação \& Linguagem, v. 10, n. 15, p. 138-160, jan./jun., 2007.

MARCELO, C. Políticas de inserción en la docencia: de eslabón perdido a puente para el desarrollo profesional docente. Santiago: Programa de Promoción de la Reforma Educativa en América Latina y el Caribe (PREAL), 2011. (Serie Documentos $n^{\circ} .52$ ).

MIZUKAMI, M. G. N.; REALI, A. M. M. R. Práticas profissionais, formação inicial e diversidade: análise de uma proposta de ensino e aprendizagem. In: MIZUKAMI, M. G. N.; REALI, A. M. M. R. (Orgs.). Aprendizagem profissional da docência: saberes, contextos e práticas. São Carlos: EdUFSCar, 2002. p. 119-137.

MONTALVÃO, E. C.; MIZUKAMI, M. G. N. Conhecimento de futuras professoras das séries iniciais do Ensino Fundamental: analisando situações concretas de ensino e aprendizagem. In: REALI, A. M. M. R.; MIZUKAMI, M. G. N. (Orgs.). Formação de professores: práticas pedagógicas e escola. São Carlos: EdUFSCar/ UNESP/CONPED, 2002. p. 101-126.

NÓVOA, A. Professores: imagens do futuro presente. Lisboa: Educa, 2009.

ORGANIZAÇÃO PARA COOPERAÇÃO E DESENVOLVIMENTO ECONÔMICOS - OCDE. Professores são importantes: atraindo, desenvolvendo e retendo professores eficazes. São Paulo: Editora Moderna, 2006.

PAPI, S. O. G. Professoras iniciantes bem-sucedidas: um estudo sobre seu desenvolvimento profissional. 2011. 300 f. Tese (Doutorado em Educação) — Pontifícia Universidade Católica do Paraná, Curitiba, 2011.

PAPI, S. O. G. Os desafios vivenciados por professoras iniciantes em seu processo de desenvolvimento profissional. In: CONGRESO INTERNACIONAL SOBRE PROFESORADO PRINCIPIANTE E INSERCIÓN PROFESIONAL A LA DOCENCIA, 3., 2012, Santiago de Chile. Anais... Santiago de Chile: UA, 2012. 1 CD-ROM. 
REALI, A. M. M. R.; TANCREDI, R. M. S. P.; MIZUKAMI, M. G. N. Programa de mentoria online: espaço para o desenvolvimento profissional de professoras iniciantes e experientes. Educação e Pesquisa, v. 34, n.1, p. 77-95, jan./abr. 2008. ROMANOWSKI, J. P.; MARTINS, P. L. O. Formação continuada: contribuições para o desenvolvimento profissional dos professores. Revista Diálogo Educacional, v. 10, n. 30, p. 285-300, mai./ago., 2010.

ROMANOWSKI, J. P. Apontamentos em pesquisas sobre formação de professores: contribuições para o debate. Revista Diálogo Educacional, v. 12, n. 37, p. 905924, set./dez. 2012.

VAILLANT, D. Atraer y retener buenos profesionales en la profesión docente: políticas en Latinoamérica. Revista de Educación, n. 340, p. 117-140, mai./ago. 2006.

VAILLANT, D.; MARCELO, C. Ensinando a ensinar: as quatro etapas de uma aprendizagem. Curitiba: Editora UTFPR, 2012.

Recebido: 09/04/2016

Received: 04/09/2016

Aprovado: 20/07/2016 Approved: 07/20/2016 